\title{
The Interaction between Metaphor and Metonymy in Emotion Category
}

\author{
Fangfang Ding \\ Sichuan Agricultural University, Ya'an, China \\ Email: 474568722@qq.com
}

\begin{abstract}
Based on the contemporary theory of metaphor and metonymy, the present dissertation makes an attempt to explore the models of interaction between metaphor and metonymy conceptualization and understanding of the concept of emotion, especially the five basic emotions: happiness/joy, anger, sadness, fear and love. The author find that the interaction between metaphor and metonymy in emotion category exists and is frequent. On the other hand, the metonymy-based metaphor is the model that the metaphor and metonymy interact with each other in emotion category.
\end{abstract}

Index Terms - metaphor, metonymy, model of interaction, metonymy-based metaphor, emotion

\section{INTRODUCTION}

Emotion is one of the most central and pervasive aspects of human experience. Since cognition can influence and be influenced by emotions, the study of human emotion constitutes one of the essential components in our probe into human cognition. Emotions and their conceptions cannot be adequately studied without reference to language of emotions. The most readily available non-phenomenal access we have to emotions is through language, and linguistic analysis has long been an essential source of information about emotion concepts. Cognitive semantics believes that the conventionalized language used to talk about the emotions can be an important tool in discovering the structure and contents of emotion concepts. The contemporary theory of metaphor regards metaphors as playing an important role in the folk and scientific conceptualization of emotion. Extensive studies have been made by Lakoff on the function of metaphor in the conceptualization of emotion. A central claim of these studies is that human emotions, which are abstract in nature, are to a great extent conceptualized and expressed by metaphor grounded in bodily experiences

As for the interaction between metaphor and metonymy, many linguists made contribution: Taylor discusses the internal variation between pre-metonymic and metonymic expressions; Louis Goossens proposes the concept metaphtonymy; Riemer, as well as Barcelona, is more interested in the ambiguities, overlappings and uncertainties of metaphor and metonymy status; Radden offers a broad canvas of all types of metonymic bases of metaphor; Dirk Geeraerts concentrates on idioms and compounds, which he subsumes under the label composite expressions, etc.

Based on the previous studies and the collection of basic emotions, this thesis employs concrete models and perspectives to focus on how to understand emotion words through these models, and the whole study will be full of concrete samples to explain the cognitive process of interpreting the emotion words. Besides, this thesis attempts to give answer to the following two questions: "In emotion expressions, are there metaphor and metonymy?" and "How do metaphor and metonymy interact in emotion category?"

\section{A COGNitive APPRoAch To METAPHOR AND Metonymy}

Metaphor is the cognitive mechanism whereby one experiential domain (Langacker, 1987) is partially mapped onto a different experiential domain, the second domain being partially understood in terms of the first one. The domain that is mapped is called the source or donor domain, and the domain onto which it is mapped, is called the target or recipient domain. Both domains have to belong to different superordinate domains. This is basically the cognitive concept of metaphor propounded by George Lakoff, Mark Johnson and Mark Turner (Johnson 1987, Lakoff \&Johnson 1980, Lakoff 1987, 1990, 1993, Lakoff \&Turner 1989, Turner 1987, 1991), as well as by Gibbs (1994), Sweetser (1991), and by other cognitive linguists who have been investigating the field in the past years.

Metonymy has not received as much attention as metaphor in cognitive linguistics, although it is probably even more basic than metaphor in language and cognition (Taylor, 1995). Metonymy is a cognitive mechanism whereby one experiential domain included in the same common experiential domain. Metonymy is a case of what Croft calls domain highlighting, whereas metaphor is a case of what he calls domain mapping. In metonymy the target domain is "highlighted," i.e. mentally activated, often with a limited discourse purpose (Lakoff 1987: 78-80), because it is this domain that is partially conceptualized by mapping onto it the source domain included in the same common domain.

The difference between the two is that while metaphor involves a mapping across different cognitive models, metonymy is a mapping within one model. One category within a model is taken as standing for another category within the same model. The main function of a metonymic expression, then, is to activate one cognitive category by 
referring to another category within the same model, and by doing that, to highlight the first category or the submodel to which it belongs.

\section{METAPHOR-METONYMY INTERACTION IN EMOTION CATEGORY}

\section{A. Basic Emotion Categories}

Within the category of descriptive emotion words, the terms can be seen as "more or less basic." Speakers of a given language appear to feel that some of the emotion words are more basic than others. More basic ones include in English anger, sadness, fear, joy, and love. Less basic ones include annoyance, wrath, rage, and indignation for anger and terror, fright, and horror for fear.

Basicness can mean two things. One is that these words occupy a middle level in a vertical hierarchy of concepts (Rosch, 1975, 1978). In this sense, anger is more basic than, for example, annoyance or emotion. Anger, being a basic-level emotion category, lies between the superordinate-level category emotion and the subordinate-level category of annoyance. This is depicted in Figure1.

The other sense of "basicness" is that a particular emotion category can be judged to be more "prototypical" of emotion than another at the same horizontal level (Rosch, 1975, 1978). This horizontal level coincides with the basic level of the vertical organization of concepts. For instance, anger is more basic in this sense than hope or pride, which in the previous sense, are on the same level. (See Figure 2)

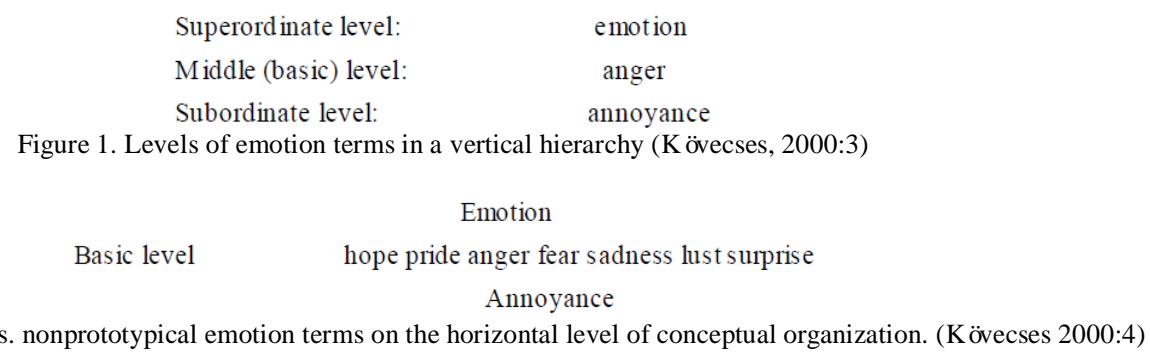

These organizations of emotion terms have been extensively studied in the past decade, e.g., Smith and Tkel-Sbal (1995) investigate the possibility that emotion terms are prototypically organized in the Micronesian language of Palau, and Smith (1995) attempts to do the same for Turkish, Fehr and Russell (1984), Shaver, Schwartz, Kirson, and O'Connor (1987) make contributions to it too. Cross-cultural research along these lines is just beginning. Using a methodology borrowed from Fehr and Russell (1984), Frijda, Markan, Sato, and Wiers (1995) arrive at five general and possibly universal categories of emotion in 11 languages. These basic emotion categories include happiness, sadness, anger, fear, and love. According to John-Laird and Oatley (1989), certain emotion terms are basic and unanalysable in the sense that they cannot be broken down into attributes or other even more basic emotions. This means that basic emotion categories like JOY or ANGER will normally be used as points of reference to describe non-basic ones like EUPHORIA, EXUBERANCE, FURY or RAGE and not vice versa. Consequently, a good way to identify basic emotions is to look at the emotion vocabulary of a language and to try to describe its emotion words in terms of attributes. This would filter out all analyzable emotion terms, so the residue of this process would be regarded as unanalysable basic emotions, which was very similar to other recent proposals and comprised all the basic emotions assembled as: SADNESS, ANGER, DISGUST/HATE, FEAR, JOY/HAPPINESS, and DESIRE/LOVE. This paper will discuss them as well.

\section{B. Interaction between Metaphor and Metonymy in Basic Emotion Category}

\section{Emotions and Physiological Metonymies}

The link between emotions and physiological symptoms reflects certain metonymic mappings, especially the cause-effect relationship observed in metonymies like THE TONGUE STANDS FOR SPEECH or THE HAND STANDS FOR WRITING. These similarities make it understandable why Kövecses and Lakoff (1987) have postulated a general metonymic principle: THE PHYSIOLOGICAL EFFECTS OF AN EMOTION STAND FOR THE EMOTION. Figure 1 gives an idea of the kinds of bodily symptoms that are related to emotions in linguistic expressions in English. The examples collected are taken from dictionaries and from informants' statements in the psychological tests. Kövecses (1990a), whose main source is Roget's Treasure, for collections of informants' statements on physiological effects. (Davitz, 1969; Shaver et al., 1987) As a result they reflect the folk theory of the physiological effects of emotions, but not necessarily objective scientific observations.

Going through Figure1, it can be singled out those three aspects between them illustrate both the potential and the limitations of physiology metonymies.

First, there are indeed bodily symptoms which seem to be helpful for a description of the conceptual structure of emotions because they are peculiar to one particular emotion: drop in temperature, sweat, dryness in the mouth, and blood leaves face for FEAR, erect posture for PRIDE, drooping posture for SADNESS, jumping up and down for JOY. Obviously these physiological phenomena help to conceptualize the emotions in question, especially where they are 
contrasted with opposites as in the case of erect vs drooping posture. Other examples are the drop of body temperature for FEAR, which is juxtaposed with its increase for ANGER, JOY, LOVE, or the paleness of the face again for FEAR, which contrasts with a red or even scarlet face and neck area for ANGER.

Then, as the example FEAR shows, an emotion category can attract conflicting metonymies, and this raises the question: Which of them is more reliable and representative? Can FEAR be connected with paralysis of the body or with flight? It might be people's preference depending on the situation, perhaps on the individual person, or it could also be a matter of sequence, with a state of paralysis functioning as preface to flight. In any case this could mean that both metonymies may play a part in the conceptualization of FEAR.

The last, and maybe the most serious problem is that many metonymies apply not just to one or a few closely related emotions but to a range of quite different emotions. ANGER, JOY and LOVE can cause an increase in body temperature, though with ANGER this would be irritating heat, while with JOY it takes the form of comfortable warmth, and with LOVE both forms are possible; all three emotions may flush one's face. ANGER and JOY, also SADNESS and FEAR can result in tears, and accelerated heartbeat and palpitations can be due to ANGER, FEAR, DISGUST and again LOVE, and general physical agitation seems to underlie all the major emotions listed in Figure 3 . This means that though they may be helpful, metonymies cannot provide the conceptual structure of emotions all by themselves. To achieve this goal, metonymies have to be supported by the conceptual potential supplied by metaphors.

\begin{tabular}{|l|l|l|}
\hline Physiological effect (source) & Emotion (target) & Example \\
\hline Increase in body temperature & ANGER, JOY, LOVE & Don't get hot under the collar. \\
\hline Drop in body temperature & FEAR & I was chilled to the bone. \\
\hline Redness in face and neck area & ANGER, JOY & She was flushed with anger. \\
\hline Blood leaves face & FEAR & She turned as pale as a sheet. \\
\hline Crying and tears & ANGER, SADNESS, FEAR, JOY & $\begin{array}{l}\text { Tears welled up in her. } \\
\text { She cried with joy. }\end{array}$ \\
\hline Sweat & FEAR & $\begin{array}{l}\text { There were sweat beads on his forehead, his } \\
\text { hands ware damp. }\end{array}$ \\
\hline Dryness of mouth & & His mouth was dry. \\
\hline $\begin{array}{l}\text { Increased pulse rate and blood pressure, } \\
\text { palpitations }\end{array}$ & FEAR & $\begin{array}{l}\text { His heart pounded. } \\
\text { He almost burst a blood vessel. }\end{array}$ \\
\hline Lapse of heartbeat & FEAR & You made my heart miss a beat. \\
\hline Erect posture, chest out & PRIDE & He swelled with pride. \\
\hline Drooping posture & SADNESS & My heart sank. \\
\hline Inability to move & FEAR & She was paralyzed with fear \\
\hline Flight & FEAR & He ran for his life. \\
\hline Jumping up and down & JOY FET, LOVE & He was jumping for joy. \\
\hline Hugging & JOY, LOVE & I could hug you all. \\
\hline General physical agitation & $\begin{array}{l}\text { ANGER, DISGUST, FEAR, JOY, } \\
\text { LOVE }\end{array}$ & $\begin{array}{l}\text { She was quivering/excited/keyed up/over } \\
\text { stimulated. }\end{array}$ \\
\hline
\end{tabular}

Figure 3. A selection of physiological metonymies for emotion (based on various publications by Kövecses, Davitz 1969 and Sha ver et al. 1987)

\section{Sample Analysis of the Interaction in Basic Emotion Category}

\section{a. Sample Analysis in ANGER}

Anger is an emotional state that may range from minor irritation to intense rage. The physical effects of anger include increased heart rate, blood pressure, and levels of adrenaline and noradrenaline.

The external expression of anger can be found in facial expressions, body language, physiological responses, and at times in public acts of aggression. Animals and humans for example make loud sounds, attempt to look physically larger, bare their teeth, and stare. Anger is a behavioral pattern designed to warn aggressors to stop their threatening behavior. Rarely does a physical altercation occur without the prior expression of anger by at least one of the participants. While most of those who experience anger explain its arousal as a result of "what has happened to them," psychologists point out that an angry person can be very well mistaken because anger causes a loss in self-monitoring capacity and objective observability. In the world of humans, the unique use of codified symbols and sounds -written and spoken language, pain or the threat of pain can be perceived from written and verbal sources. Humans may not perceive an immediate physical threat, but pain can be felt psychologically. Due to humans' capacity to imagine the distant future, the threat of pain can also arise purely from the imagination, and not be based on anything happening in the immediate present. In humans, anger often arises when another human being is perceived to violate expected behavioral norms related to social survival. These violations break social or interpersonal boundaries, or may be ethical or legal violations.

Metonymic-based metaphor is a frequent type in the figurative expressions. A great many of metaphors have been found to have a metonymic basis. The classic case of this interaction is the link between the metonymy based on body heat, and heat metaphor, as described by Kövecses and Lakoff (1987).

The conventional expressions used to talk about anger seem so diverse that finding any coherent system would seem impossible. Here are some sample sentences found in Roget's University Thesaurus, most of which have something to do with anger. They seem too diverse to reflect any coherent cognitive model.

a. He lost his cool. 
b. She was looking daggers at me.

c. E almost burst a blood vessel.

d. He was foaming at the mouth.

e. You're beginning to get to me.

f. You make my blood boil.

\section{b. Physiological Effect of ANGER}

Physiological responses to anger include an increase in the heart rate, preparing the person to move, and increase of the blood flow to the hands, preparing them to strike. Perspiration increases, particularly when the anger is intense. A common metaphor for the physiological aspect of anger is that of a hot fluid in a container. According to Novaco (2000), "Autonomic arousal is primarily engaged through adrenomedullary and adrenocortical hormonal activity. The secretion by the andrenal medulla of the catecholamines, epinephrine, and norepinephrine, and by the andrenal cortex of glucocorticoids provides a sympathetic system effect that mobilizes the body for immediate action (e.g. the release of glucose, stored in the liver and muscles as glycogen). In anger, the catecholamine activation is more strongly norepinephrine than epinephrine (the reverse being the case for fear). The adrenocortical effects, which have longer duration than the adrenomedullary ones, are modiated by secretions of the pituitary gland, which also influences testosterone levels. The pituitary-adrenocortical and pituitary-gonadal systems are thought to affect readiness or potentiation for anger responding."

The analysis is with the folk theory of the physiological effects of anger. The physiological effects of anger are increased body heat, increased internal pressure, like blood pressure and muscular pressure, agitation and interference with accurate perception; as anger increases, its physiological effects increase; there is a limit beyond which the physiological effects of anger impair normal functioning. This folk theory is used to tell when someone is angry on the basis of their appearance-as well as to signal anger or hide it. In doing this, a general metonymic principle must be made use of: THE PHYSIOLOGICAL EFFECTS OF AN EMOTION STAND FOR THE EMOTION.

By using this principle, the folk theory given above yields a system of metonymies for anger (Lakoff, 1987:382-383):

Body heat

a. Don't get hot under the collar.

b. Billy's a hothead.

c. They were having a heated argument.

d. When the cop gave her a ticket, she got all hot and bothered and started cursing.

Internal pressure

a. Don't get a hernia!

b. When I found out, I almost burst a blood vessel.

c. He almost had a hemorrhage.

Increased body heat and blood pressure is assumed to cause redness in the face and neck area and such redness can also metonymically indicate anger.

Redness in face and neck area

a. She was scarlet with rage.

b. He got red with anger.

c. He was flushed with anger.

Agitation

a. She was shaking with anger.

b. I was hopping mad.

c. He was quivering with rage.

d. He's all worked up.

e. There's no need to get so excited about it!

f. She's all wrought up.

g. You look upset.

Interference with accurate perception

a. She was blind with rage.

b. I was beginning to see red.

c. I was so mad I couldn't see straight.

Each of these expressions indicates the presence of anger by its supposed physiological effects.

c. Interaction between Metaphor and Metonymy in ANGER

The folk theory of physiological effects, especially the part that emphasizes HEAT, forms the basis of the most general metaphor for anger: ANGER IS HEAT (Lakoff, 1987). But this rather abstract principle is made much more accessible if it can be imagined in the forms of a fire and a hot fluid. There are two versions of this metaphor, one where the heat is applied to fluids and the other where it is applied to solids. When it is applied to fluids, ANGER IS THE HEAT OF A FLUID IN A CONTAINER can be reached. The specific motivation for this consists of the HEAT, INTERNAL PRESSURE, and AGITATION parts of the folk theory. When ANGER IS HEAT is applied to solids, that is the version ANGER IS FIRE, which is motivated by the HEAT and REDNESS aspects of the folk theory of 
physiological effects. This is illustrated in Figure 4.
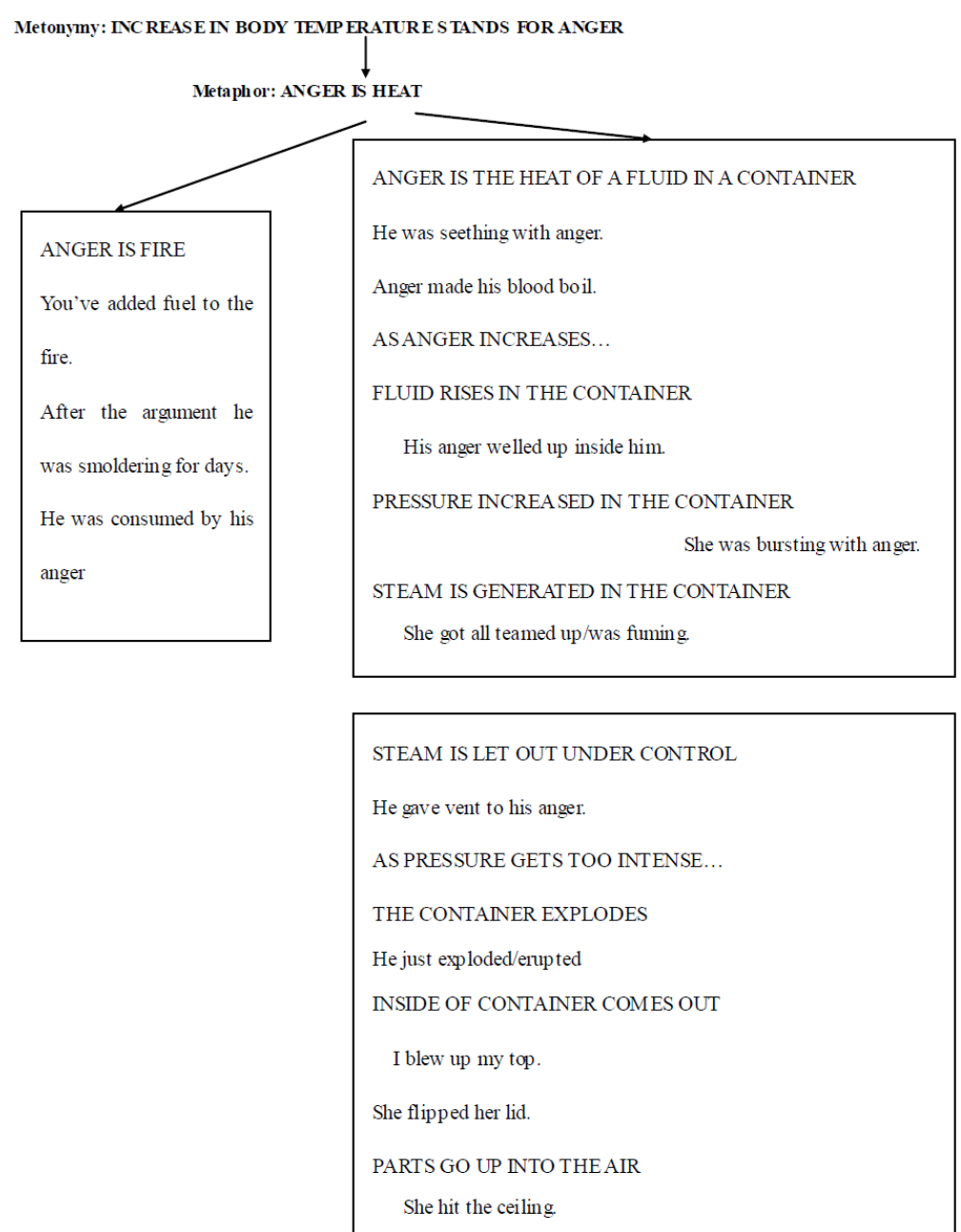

Figure 4

Seen from this table, it is quite clear that the first of these two metaphorical applications ANGER IS FIRE is less developed than the second one ANGER IS THE HEST OF A FLUID IN A CONTAINER. Although FIRE is an important basic level event category combining a number of action and object categories, the various stages of kindling, maintaining and extinguishing a fire and the fuels involved in an ordinary fire do not seem to provide a very rich category structure which could be mapped onto the ANGER category. In contrast, the second HEAT metaphor, ANGER IS THE HEAT OF A FLUID IN A CONTAINER, has a much richer conceptual background. One reason is that many more source categories are involved, especially highly suggestive basic level categories like BOIL, RISE, STEAM, FUME, BURST, EXPLODE, for which most informants would be able to call up substantial attribute lists. More important still, this metaphor relies on one of the most basic spatial experiences, the be-in-something relation, which was introduced above as the image schema underlying the CONTAINER metaphor. Finally, the HEAT OF A FLUID metaphor is combined with another powerful metaphor, THE BODY IS A CONTAINER FOR EMOTINS, and this is linked up with the very basic and vital category BODY.

The result of this powerful metaphorical potential is the large number of derived metaphor listed in Figure 4 . In the case of ANGER, the roles of metaphor and metonymy playing are equally important. The physiological effects mentioned above are counterbalanced by the heat metaphors and a series of other metaphors, such as:

ANGER IS AN ACTIVE ENEMY

I'm struggling with my anger.

He was battling with his anger.

She fought back her anger.

ANGER IS A DANGEROUS AGGRESSIVE ANIM

He has a ferocious temper.

It's dangerous to arouse his anger.

His anger grew.

\section{Sample Analysis in FEAR}

Fear is an emotional response to threats and danger. It is a basic survival mechanism occurring in response to a 
specific stimulus, such as pain or the threat of pain.

Similar to the emotion category ANGER, there are a great number of conventional expressions about fear.

fear follows you home

face the fear

\section{a. Physiological Effect of FEAR}

In fear, one may go through various emotional stages. A good example of this is the cornered rat, which will try to run away until it is finally cornered by its predator, at which point it will become belligerent and fight back with heavy aggression until it either escapes, or is captured.

The same goes for most animals. Humans can become very intimidated by fear, causing them to go along with another's wishes without regard to their own input. They can also become equally violent and even deadly; it is an instinctive reaction caused by rising adrenaline levels, rather than a consciously thought-out decision. This is why, in many related cases, the death penalty cannot be made in a court of law.

The facial expression of fear includes the following components:

- One's eyes widen (out of anticipation for what will happen next).

- The pupils dilate (to take in more light).

- The upper lip rises.

- The brows draw together.

- Lips stretch horizontally.

The physiological effects of FEAR are drop in body temperature, blood leaves face, sweat, dryness of mouth, increased pulse rate and blood pressure, lapses of heartbeat, inability to move, flight, etc.

Also by using the principle that the physiological effects of an emotion stand for the emotion, the folk theory given above yields a system of metonymies for fear.

Drop in body temperature

I was chilled to the bone.

Blood leaves face

She turned pale/white as a sheet.

Sweat

There were sweat beads on his forehead.

His hands were damp.

Dryness of mouth

His mouth was dry.

Lapses of heartbeat

You made my heart miss a beat.

Inability to move

She was paralyzed with fear.

Flight

He ran for his life.

Increased pulse rate and blood pressure, palpitations

His heart pounded.

All these expressions are the illustrations of the physiological effect of FEAR. The category FEAR, which commands a large number of metonymies, does not seem to attract many conceptual metaphors. But beside metonymy, doesn't metaphor do any contribution to FEAR?

b. The Interaction between Metaphor and Metonymy in FEAR

The category FEAR, which commands a large number of metonymies, does not seem to attract many conceptual metaphors. However, are the expressions all pure metonymies in this category? Of course not. At least, FEAR IS A NATURAL FORCE, FEAR IS A VICIOUS OPPONENT OR TORMENTER and FEAR IS A TRICKSTER are the exceptions.

FEAR IS A NATURAL FORCE: fear overwhelms you engulfs you and sweeps over you

FEAR IS A VICIOUS OPPONENT OR TORMENTER: fear preys, fear creeps up on you

FEAR IS A TRICKSTER: fear may deceive you

First, FEAR IS A NATURAL FORCE is taken for example: 


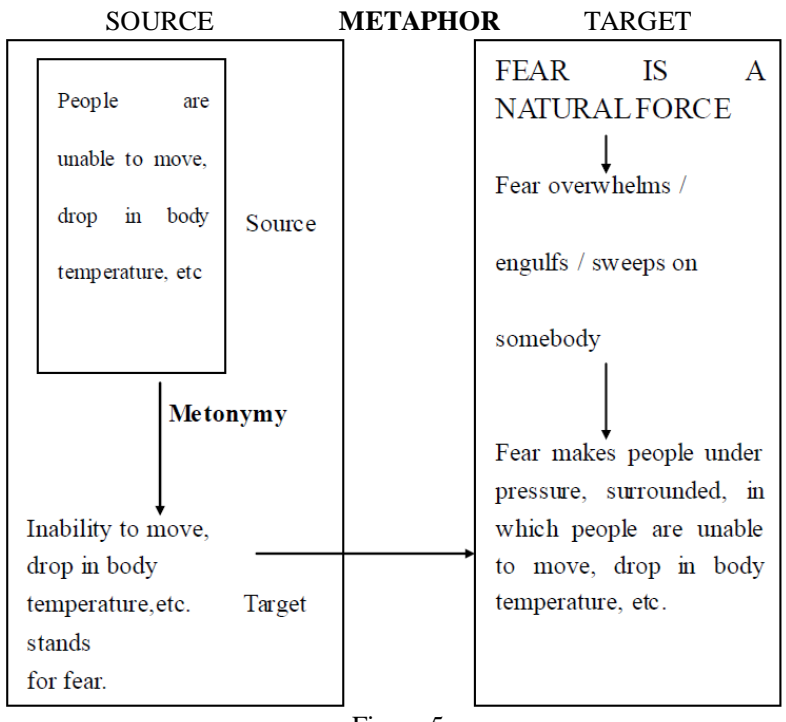

Figure 5

Seen from figure 5, source domain and target domain of the metonymy INABILITY TO MOVE STANDS FOR FEAR are included in the source domain of the metaphor FEAR IS A NATURAL FORCE. That is to say the metaphor FEAR IS A NATURAL FORCE is based on INABILITY TO MOVE STANDS FOR FEAR. It can be found that in this expression, the roles metaphor and metonymy plays are equal important.

The analysis of FEAR IS A VICIOUS OPPONENT OR TORMENTER and FEAR IS A TRICKSTER is illustrated as follows:

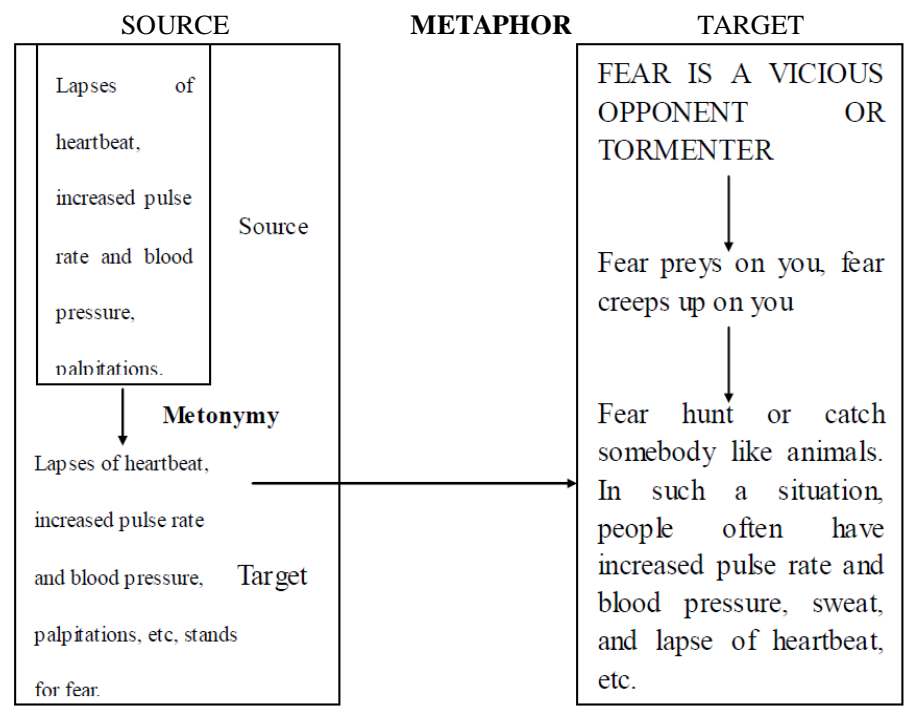

Figure 6

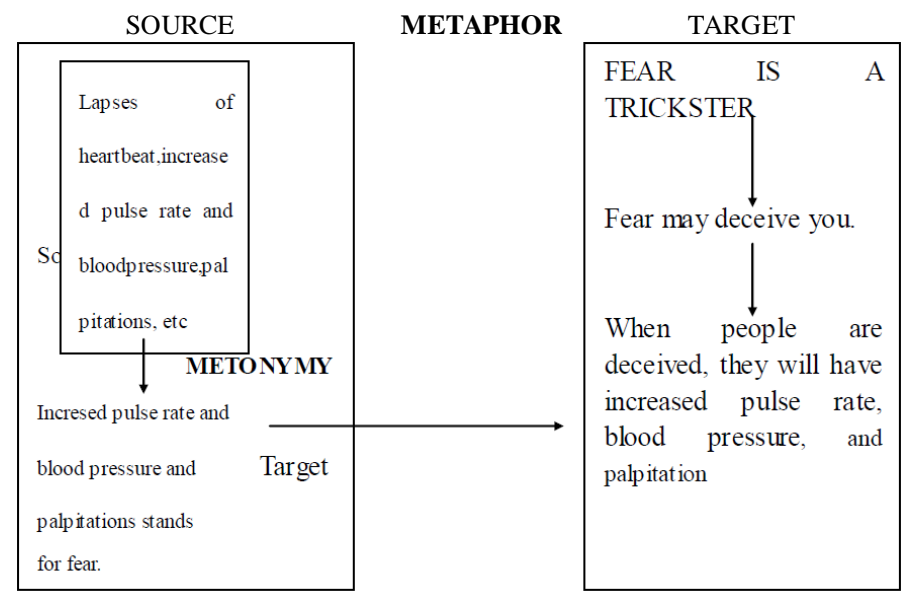

Figure 7 


\section{Sample Analysis in JOY/HAPPINESS}

Happiness is an emotion associated with feelings ranging from contentment and satisfaction to bliss and intense joy. A variety of philosophical, religious, psychological and biological approaches have been taken to defining happiness and identifying its sources. Philosophers and religious thinkers have often defined happiness in terms of living a good life, or flourishing, rather than simply as an emotion. Happiness in this older sense was used to translate the Greek Eudaimonia, and is still used in virtue ethics. In everyday speech today, however, terms such as well-being or quality of life are usually used to signify the classical meaning, and happiness is reserved for the felt experience or experiences that philosophers historically called pleasure. Joy is an emotion of great happiness.

\section{a. Physiological Effect of JOY/HAPPINESS}

In addition to the above happiness metaphors, Kövecses (1991)also exemplifies the existence of conventionalized expressions metonymic of the emotion of happiness. As is the case with anger, these metonymic expressions are based on some behavioral reactions to happiness, such as jumping, dancing, smiling, and bright eyed, etc. Thus, in English there are:

Jumping

a. He jumped for joy.

b. He was leaping with joy.

Dancing

c. We were dancing with joy.

d. They kicked up their heels.

e. She had a ball.

Smiling

f. She was smiling with happiness.

g. They were all smiles.

h. He grinned from ear to ear.

i. He was all teeth.

Reactions in eyes

j. Amusement gleamed in his eyes.

$\mathrm{k}$. His eyes glinted when he saw the money.

1. His eyes were shining.

$\mathrm{m}$. Her eyes were sparkling like diamonds.

Increase in body temperature

$\mathrm{n}$. His body went hot when he heard the good news.

Redness in face and neck area

o. She was flushed with joy.

Crying and tears

p. She cries with joy.

Hugging

q. I could hug you all.

b. Interaction between Metaphor and Metonymy in JOY/HAPPINESS

According to Lakoff and Johnson (1980) and Kövecses (1991), a major conceptual metaphor for the notion of happiness/joy in English is orientational: HAPPY IS UP. Under this conceptual metaphor some conventionalized expressions are:

a. I'm feeling up.

b. That boosted my spirits.

c. My spirits rose.

d. Thinking about her always gives me a lift.

e. We had to cheer him up.

f. They were in high spirits.

Closely related to the HAPPY IS UP metaphor is another conceptual metaphor of upward orientation: BEING HAPPY IS BEING OFF THE GROUD (Kövecses, 1991). Instances of this type include:

a. I was flying high.

b. She was on cloud nine.

c. I'm six feet off the ground.

d. We were in the clouds.

e. I was just soaring with happiness.

f. After the exam, I was walking on air for days.

g. They were riding high.

h. I was floating.

These expressions are in effect grounded in our bodily experience. They arise from the fact that as humans have upright bodies. The erect posture typically goes with positive emotional as well as physical states, whereas the opposite 
is true with a drooping posture.

The metaphors mentioned above are metonymic-based. Take the sentence I'm six feet off the ground for example, which is illustrated in Figure8:

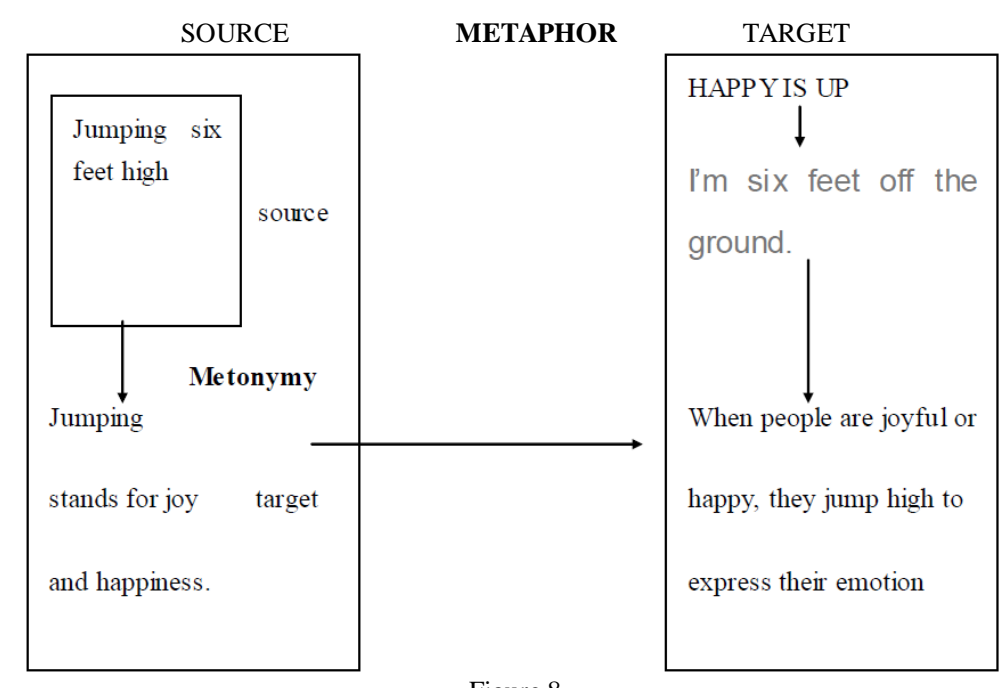

Figure 8

Kövecses (1991) suggests that another major metaphorical concept of happiness in English is HAPPINESS IS LIGHT, under which the metaphorical expressions are, for instance:

a. When she heard the news, she lit up.

b. Noting to worry about, brighten up.

c. He radiates joy.

d. She has a sunny smile.

e. You are the sunshine in my life.

f. He was gleaming.

g. She was shinning with joy.

Again, these expressions are motivated by the experiential basis underlying them. When one becomes happy, his or her complexion and eyes turns brighter. The brightness is then an assumed expressive response observed in happiness. The light appears to derive from the internal energy characteristic of a happy person. This kind of interaction between metaphor and physiological metonymy is as follows:
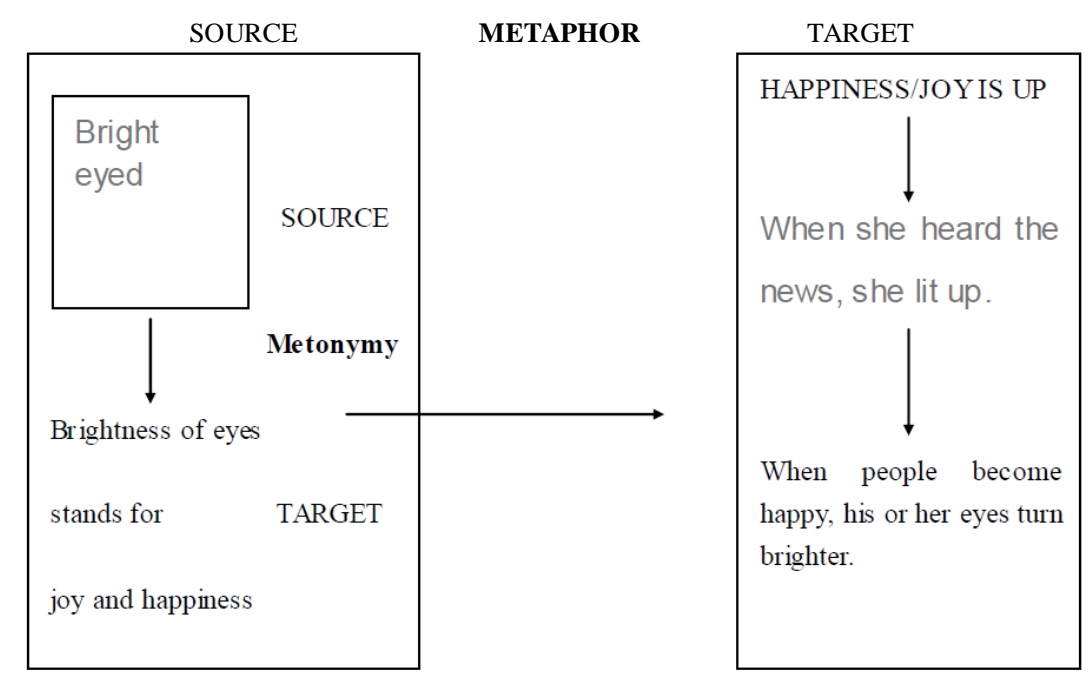

Figure 9

A third major metaphor conceptualizing happiness is the CONTAINER type, namely HAPPINESS OR JOY IS A FLUID IN A CONTAINER, which in fact is a specific-level instantiation of the more general metaphor THE EMOTION ARE FLUID IN A CONTAINER. The conventionalized linguistic expressions encoding this conceptual metaphor in English include:

a. We were full of joy.

b. The sight filled them with joy.

c. Joy welled up inside her. 
d. I brimmed over with joy when I saw her.

e. She couldn't contain her joy any longer.

f. He was overflowing with joy.

g. He was bursting with joy.

h. My heart is filled with joy.

The container is the body in a-g and the heart in h. Apparently, the CONTAINER metaphor here is very different from the one with anger. As Kövecses (1991) points out, the emotion of anger is conceived of as the hot fluid inside a closed container, but with happiness the temperature of the fluid inspecific. It can be assumed that it is warm rather than too hot or too cold. Kövecses (1991) also observes that the container for happiness exists in two varieties. In one the container is open and the emotion-fluid "overflows" when its quantity exceeds the capacity of the container, as in d-f. In the other the container is closed and "bursting" with increasing amount of emotion-fluid inside, as in g. This indicates that the person is unable to control his or her emotion. What distinguishes this container from the anger one, however, is that it will not explode since there is no excessive internal pressure caused by too much heat. Generally, happiness as a positive emotion provided people with more vitality rather than destructive force.

As for the conceptual metaphor HAPPINESS/JOY IS A FLUID IN CONTAINER, there are also the physiological metonymies existing. The sentence She couldn't contain her tears any longer when she saw her mother will be in analysis, which is shown in Figure 10:

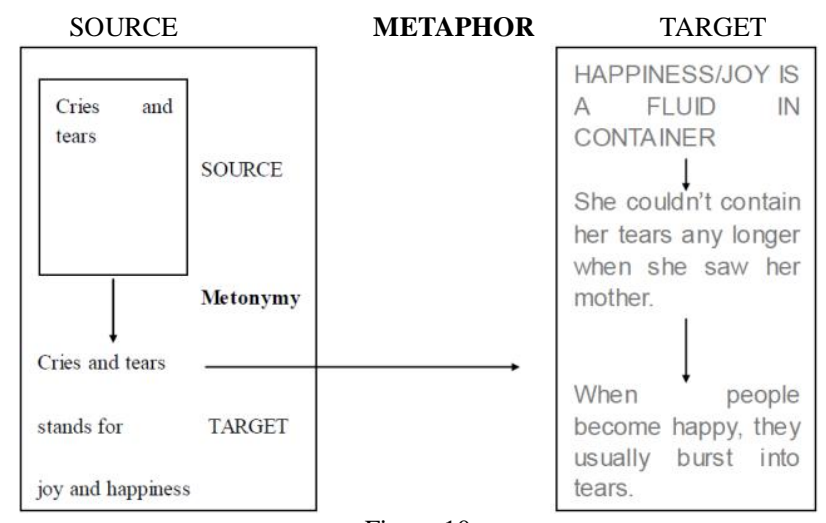

Figure 10

\section{Sample Analysis in LOVE}

Love is any of a number of emotions and experiences related to a sense of strong affection. The word love can refer to a variety of different feelings, states, and attitudes, ranging from generic pleasure ("I loved that meal") to intense interpersonal attraction ("I love my girlfriend"). This diversity of meanings, combined with the complexity of the feelings involved, makes love unusually difficult to be consistently defined, even compared with other emotional states.

As an abstract concept, love usually refers to a deep, ineffable feeling of tenderly caring for another person. Even this limited conception of love, however, encompasses a wealth of different feelings, from the passionate desire and intimacy of romantic love to the nonsexual emotional closeness of familial and Platonic love to the profound oneness or devotion of religious love. Love in its various forms acts as a major facilitator of interpersonal relationships and, owing to its central psychological importance, is one of the most common themes in the creative arts.

a. The Physiological Effect of LOVE

Some conventional metonymies in English are used to describe love. Here are some examples:

Physical closeness:

a. I want to be with you all my life.

b. He follows her everywhere.

c. They walked along the Danube holding hands.

d. I want to hold you in my arms forever.

Body heat:

a. I felt hot all over when I saw her.

b. You really have the hots for her, don't you?

c. It was a torrid relationship.

Impeded-perception

a. He saw nothing but her.

b. I only have eyes for her.

Increased heart-rate

a. She had palpitations.

b. He's a heartthrob.

c. His heart was throbbing with love. 


\section{Hugging}

a. I could hug you all.

b. Interaction between Metaphor and Metonymy in LOVE

With regard to the number of conceptual metaphors, LOVE surpasses all other emotions. Many of these metaphors are shared with JOY. In addition, there is, quite naturally, a range of metaphors which is based on the metonymic relationship with sexual desire, such as LOVE IS A NUTRIENT, LOVE IS APPETIZING FOOD, and there are flattering comparisons with magic and deity, as LOVE IS MAGIC, THE OBJECT OF LOVE IS A GODDESS, with the poetic sources still particularly noticeable. What is unusual in comparison with JOY is that LOVE is not only structured by positive metaphors, but also seems to attract a full range of negative conceptual metaphors, among them LOVE IS WAR, LOVE IS HUNTING, LOVE IS A DESIRE. This also applies to the CONTAINER metaphors, where LOVE is characterized not only as a fluid overflowing from the container, but alternatively by the explosion of the container, which is also typical of the ANGER category.

Are there metaphors listed above metonymy based? The answer is given below. In the metaphor LOVE IS FIRE, its physiological base is body heat. For example, His heart is on fire. When somebody falls in love, he or she will get excited, which should fasten their blood flowing, so that he or she might feel hot. And if something is put on fire, it must get hotter.

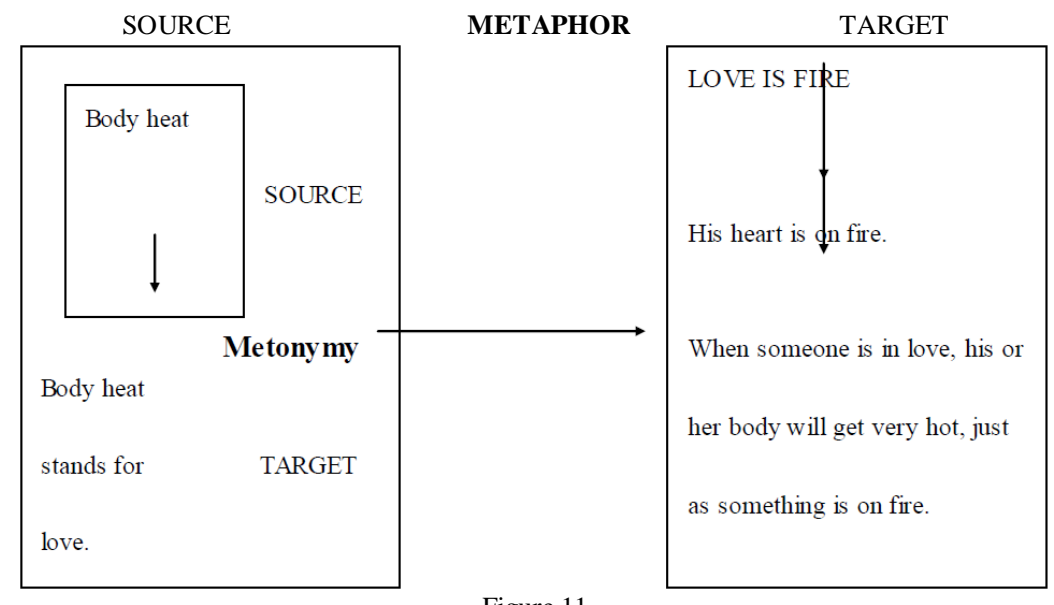

Figure 11

As for the metaphor LOVE IS A MAGIC, there is also metonymy included. Usually, magic shows are mysterious and exciting. People often feel the heart beat quickly when watching them. At the same time, it is common for people to have palpitations as they see their lovers. This kind of interaction is illustrated in Figure 12.

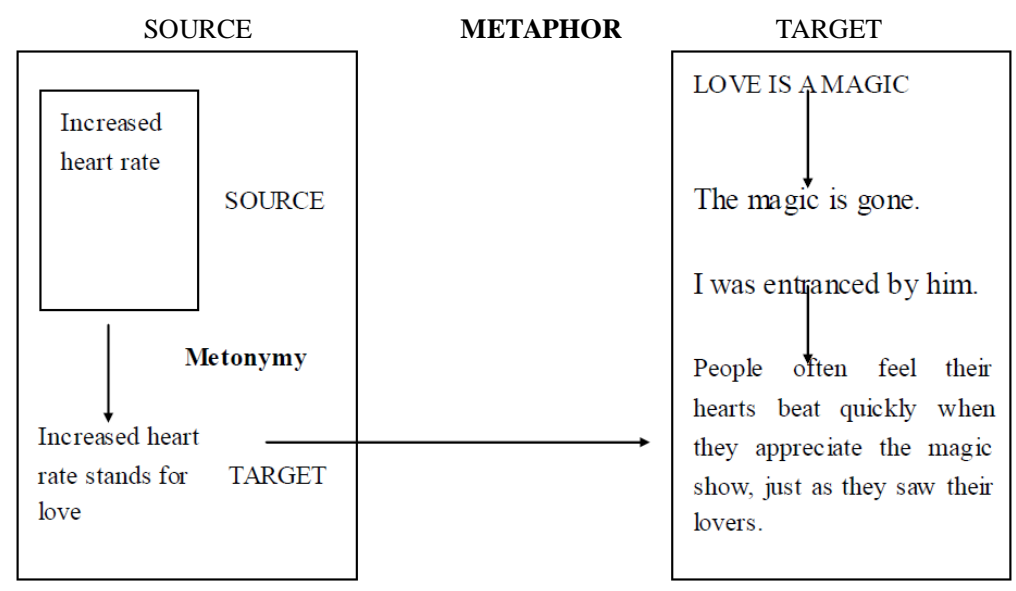

Figure 12

The last example is about one of the most often used metaphor LOVE IS A JOURNEY, which is based on the metonymy PHYSICAL CLOSENESS STANDS FOR LOVE. Physical closeness is quite ordinary to lovers. On the contrary, if there is always something setting them apart, they may have trouble in their relationships. Also going ahead hand in hand means the two people are in good relationship, but being separated means the bad condition. The relation between LOVE IS A JOURNEY and PHYSICAL CLOSENESS STANDS FOR LOVE can be understood better in Figure 13. 


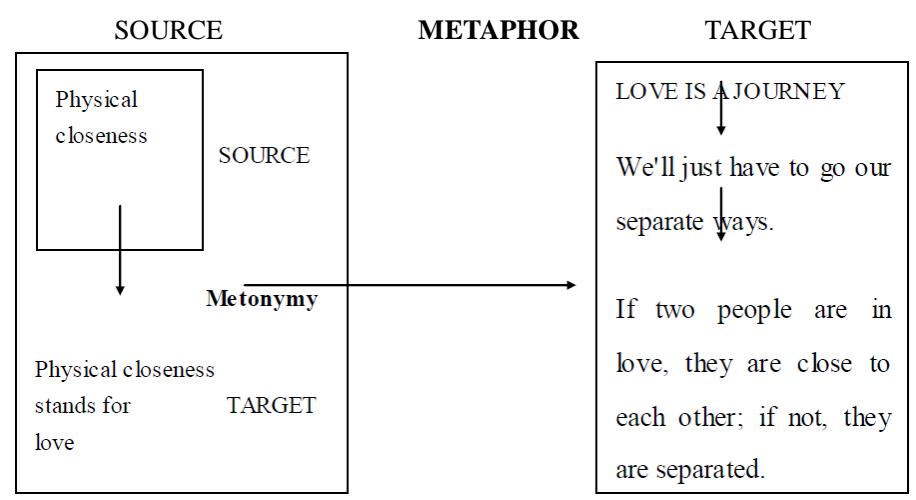

Figure 13

Although the number of metonymy in LOVE is relatively small, the large number of metaphors in this category depends on these metonymies to some extend. Some metaphors such as LOVE IS FIRE and LOVE IS A MAGIC, etc, can not be structured with out them.

\section{Sample Analysis in SADNESS}

The emotion "sadness" shares a myriad of synonymies like melancholy, gloom, grief, lament, sorrow, dejection, depression, downcast, dismay, disconsolation, pensiveness etc.. The following definition of "sadness" is taken from Webster's Third New International Dictionary.

Sadness is an emotional attitude characterized by an unpleasant feeling tone and expressing itself in sighing, weeping, as well as passivity and diminished tone of the voluntary muscles. It is the most general word used here.

Sadness is an emotion characterized by feelings of disadvantage, loss, and helplessness. When sad, people often become quiet, less energetic, and withdrawn. Sadness is considered to be the opposite of happiness, and is similar to the emotions of sorrow, grief, misery, and melancholy. A philosopher called Baruch Spinoza defined sadness as the "transfer of a person from a large perfection to a smaller one." Sadness can be viewed as a temporary lowering of mood (colloquially called "feeling blue"), whereas clinical depression is characterized by a persistent and intense lowered mood, as well as disruption to one's ability to function in day to day matters. Sadness can lead to disappointment with life, which is a very critical position.

\section{a. Physiological Effect of SADNESS}

Compared with the emotion category LOVE, the number of metonymies in SADNESS is even smaller. However, it is also governed by the general metonymic principle: THE EFFECT OF EMOTION STAND FOR THIS EMOTION.

Crying and tears

She cried with sadness.

Her eyes were full of tears when she heard the news.

Drooping posture

My heart sank.

I feel low.

Like all the other metonymies, the metonymies on sadness single out those prominent properties directly related to sadness to present the stand-for relationship. And this phenomenon is believed to happen to other emotions. However differences are supposed to exist between emotion metonymies and other metonymies. First, those prominent properties in emotion metonymy are not so prominent to deserve a prototypical position as those in other metonymies. What is meant here is that the notion of "prototype effect" is over much for metonymies on sadness or other emotions, because those features related to sadness, like darkening complexion, reduction of body shape, are more salient to be perceived. Second, those features in sadness metonymies serve as the cause that triggers the emotion or the direct results come from the emotion, which is not necessarily, the case for other metonymies.

\section{b. Interaction between Metaphor and Metonymy in Sadness}

Even though the physiological effect of sadness is not so much, conceptual metaphors on sadness is a complex system. In order to make a systematic study of those sadness metaphors, I sorted them into categories according to the underlying conceptual structure.

\section{SADNESS IS SUBSTANCE IN A CONTAINER}

a. Age is full of care.

b. But when the melancholy fit shall fall

Sudden from heaven like a weeping cloud,

That fosters the droop-headed flowers all,

And hides the green hill in an April shroud;

Then glut thy sorrow on a morning rose,

SADNESS IS A CONTAINER

a. Was the worst pang that sorrow ever bore, Save one, one only, when I stood forlorn.

b. And he, repulsed.- - a short tale to make,--Fell into a sadness, then into a fast. 
c. Sweet though in sadness.

Body in this sense is viewed as a container. If body capacity is large enough to hold sadness inside, it is all right to say "full of care"; if not, and the amount exceeds, and then it has to be "glut". The way sadness exceeds the capacity of body is different from anger. Anger is more likely to be packed in a closer container in high temperature and with a quick expansion, finally ends with a "burst" or "explosion" as a result of excessive internal pressure. But sadness tends to be more placidly accumulated and then overflows steadily. In SADNESS IS A CONTAINER, sadness is represented by bounded space, and experiencing this kind of emotional state is represented by entering into a location.

Though the number of metaphor and metonymy is far from balanced in SADNESS, the fact that some metaphors are based on metonymy is true as well. Some sample analyses are illustrated as follows.

The metaphor SADNESS IS SUBSTANCE IN A CONTAINER, for example, Her eyes were a swimming pool when she was seeing the moving story, is combined with the metaphor TEARS AND CRIES STAND FOR SADNESS. It can be noticed first that SADNESS IS SUBSTANCE IN A CONTAINER is from the general metaphor in emotion category HUMAN BODY IS A CONTAINER and EMOTION IS A SUBSTANCE IN A CONTAINER. In this metaphor, one's eyes are metaphorized as the swimming pool, which is full of water. As for the metonymic basis, when one is very sad, his or her eyes are prone to be full of tears, which is governed by the general metonymy principle: THE EFFECT OF EMOTION STAND FOR THIS EMOTION. So the metonymy-based metaphor can be understood as Figure 14.

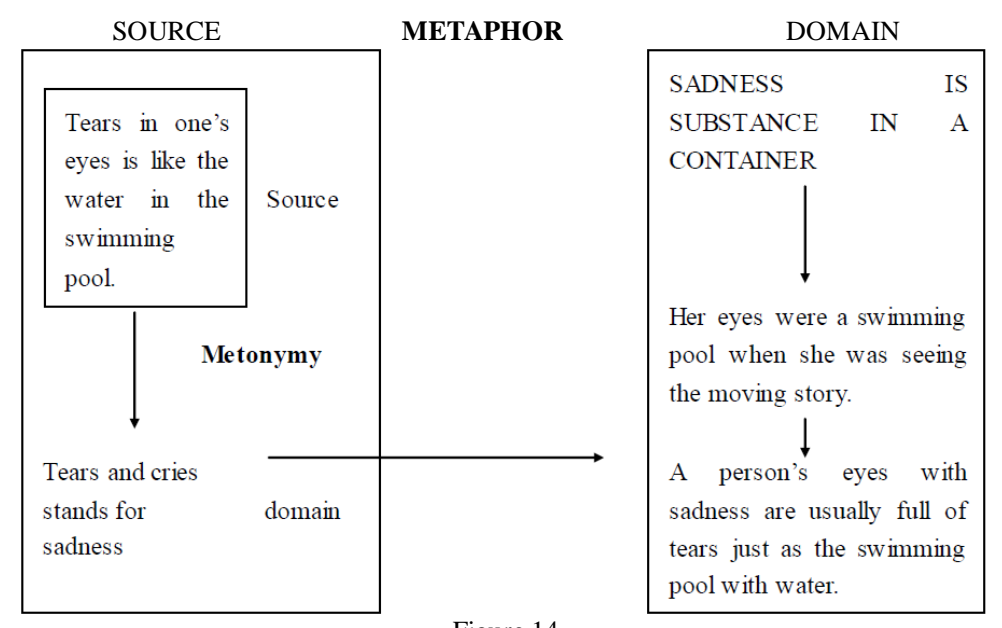

Figure 14

Also in the metaphor SADNESS IS ANIMATE BEING, sadness is seen as a weak patient. When someone is ill, he or she must be in low spirit and his or her body in a dropping posture. Similarly, a sad person cannot be happy up and his or her body must be in a dropping posture as well. So it can be concluded that SADNESS IS A WEAK PATIENT has the metonymic basis DROPPING POSTURE STANDS FOR SADNESS.

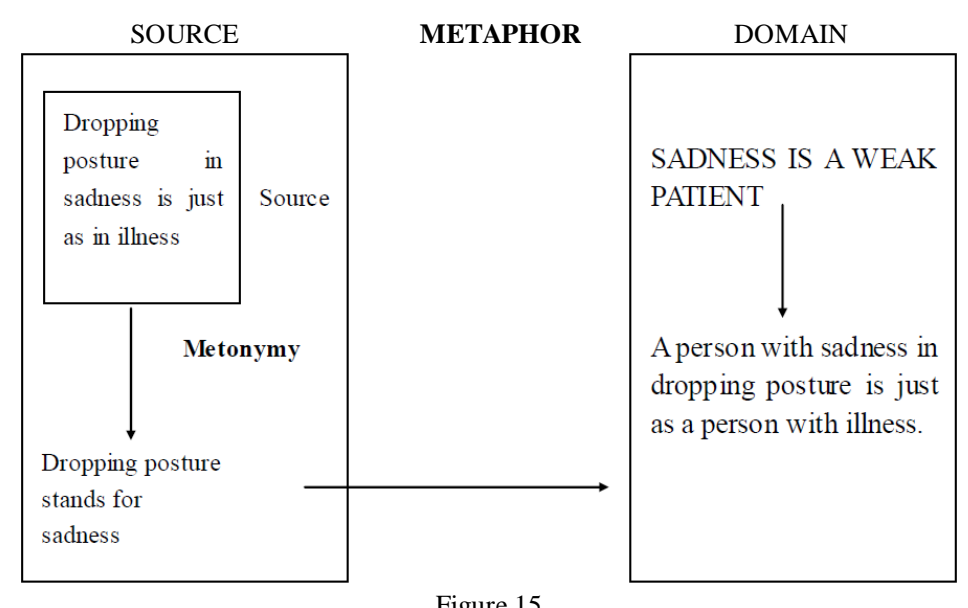

Figure 15

And the metaphor SADNESS IS A BURDEN can also be understood as SADNESS IS A WEAK PATIENT. Because a heavy burden may make a person who takes it feel so tied that his or her body and mind is in a low level relatively.

\section{CONCLUSION}

One field in which a co-occurrence of metaphors and metonymies is particularly frequent is the field of emotion category. Researches reveal that in English the basic emotions include anger, sadness, fear, joy/ happiness, and love. 
Starting from the above standpoint, this dissertation conducts a study on the interaction between metaphor and metonymy in emotion category in English.

In the first place, the study of metaphor and metonymy in emotion category shows that metaphor, as well as metonymy, is the primary device for understanding the abstract concepts.

Secondly, a lot of metaphors are triggered off by the physiological metonymies in emotion category, which shows that metaphor and metonymy are not absolutely separated but interact with each other.

With all the findings, the present study still has a few limitations. On the one hand, as is illustrated above, the models of interaction is various. No one set of patterns has been appreciated by all the linguists and no one can be applied to all the fields. The pattern chosen in this dissertation is just for easily expressed the interaction in emotion category. Whether other patterns can be used in emotion terms calls for further study. On the other hand, this paper is limited to the metonymy-based metaphor; the interaction from metaphor to metonymy will be the next object of the study.

\section{REFERENCES}

[1] Albertazzi, L. (2000). Meaning and Cognition: A Multidisciplinary Approach. Amsterdam: John Benjamins.

[2] Athanasiadou, A \& E. (1998). Tabakowska. Speaking of Emotions: Conceptualisation and Expression. Berlin: Walter de Gruyter.

[3] Barcelona, A. (2000). Metaphor and Metonymy at the Crossroads: A Cognitive Perspective. New York: Mouton de Gruyter.

[4] Barcelona, A. (2003). Metonymy in Cognitive Linguistics: An Analysis and a Few Modest Proposals. Motivation in Language: Studies in Honor of Günter Radden. Amsterdam: John Benjamins.

[5] Croft, W. \& D. A.Cruse.( 2004). Cognitive Linguistics. Cambridge: Cambridge University Press.

[6] Deignan, A. (2005). Metaphor and Corpus Linguistics. Amsterdam: John Benjamins.

[7] Dirven, R \& R. Porings. (2003). Metaphor and Metonymy in Contrast and Comparison. New York: Mouton de Gruyter.

[8] Fussell, S. R. (2002). The Verbal Communication of Emotions: Interdisciplinary Perspectives. New Jersey: Lawrence Erlbaum Associates.

[9] Geeraerts, D \& H. Cuyckens. (2007). The Oxford Handbook of Cognitive Linguistics. Oxford and New York: Oxford University Press.

[10] Haser, V. (2005). Metaphor, Metonymy, and Experientialist Philosophy: Challeging Cognitive Semantics. Berlin: Walter de Gruyter.

[11] Indurkhya,B.(1992). Metaphorand Cognition: an interactionist approach. Dordrecht/Boston/London: Kluwer Academic press.

[12] Johnson, M. (1987). The Body in the Mind. Chicago: University of Chicago Press.

[13] Knowles, M \& R. Moon. (2006). Introducing Metaphor. London: Routledge.

[14] Kövecses, Z. (1988). The Language of Love: The Semantics of Passion in Conversational English. Associated University Presses.

[15] Kövecses, Z. (2000). Metaphor and Emotion: Language, Culture, and Body in Human Feeling. Cambridge: Cambridge University Press, 4.

[16] Kövecses, Z. (2002). Metaphor: A Practical Introduction. Oxford: Oxford University Press.

[17] Kövecses, Z. (2005). Metaphor in Culture: Universality and Variation. Cambridge: Cambridge University Press.

[18] Kövecses, Z.(2006). Language, Mind, and Culture: A Practical Introduction. Oxford: Oxford University Press.

[19] Lakoff, G. (1987). Women, fire and dangerous things: What categories reveal about mind. Chicago and London: University of Chicago Press, 78-80, 380-485.

[20] Lakoff, G. \& Johnson, M. (1980). Metaphors We Live By. Chicago: The University of Chicago Press.

[21] Lakoff, G \& Turner, M. (1989). More than Cool Reason. Chicago: University of Chicago Press.

[22] Lewis, M \& J. Haciland-Jones. (2000). Handbook of Emotions. New York: Guilford Press.

[23] Lyons, W. (1980). Emotion. Cambridge: Cambridge University Press.

[24] Mascolo, F\&S. Griffin. (1998). What Develops in Emotional Development? Berlin: Springer.

[25] Novaco, R. W. (2000). Anger. Encyclopedia of Psychology. Oxford: Oxford University Press.

[26] Ortony, A. (1979). Metaphor and Thought. Cambridge: Cambridge University Press.

[27] Panther, K \& G. Radden. (1999). Metonymy in Language and Thought. Amsterdam: John Benjamins.

[28] Ricoeur, P. (1986). The Rule of Metaphor. London: Routledge \& Kgan Paul Ltd.

[29] Russell, J, J. Fernandez-Dols, A. Manstead \& J. Wellenkamp. (1995). Everyday Conceptions of Emotion: An Introduction to the Psychology, Anthropology and Linguistics of Emotion. Berlin: Springer.

[30] Saeed, J. I. (2000). Semantics. Beijing: Foreign Language Teaching and Research Press.

[31] Taylor, J \& R. Maclaury. (1995). Language and the Cognitive Construal of the World. Berlin: Walter de Gruyter.

[32] Ungerer, F \& H. J. Schmid. (2001). An Introduction to Cognitive Linguistics. Beijing: Foreign Language Teaching and Research Press.

[33] Witting, M. A. (2007). Metaphor-The Structure of the Domain "Anger". GRIN Verlag.

[34] Yu Ning. (2003). The Contemporary Theory of Metaphor: A Perspective from Chinese. Amsterdam: John Benjamins.

Fangfang Ding was born in Chongqing, China, in 1980. She received her MA in linguistics from the Southwest University, China in 2009.

She is currently a lecturer in Sichuan Agricultural University, China. Her research interest is cognitive linguistics. 